\title{
BMJ Open Cross-sectional seroprevalence study of antibody to Bordetella pertussis toxin in western Saudi Arabia: is there a need for a vaccine booster dose for adolescents and young adults?
}

\author{
Fayssal Farahat (D) , ${ }^{1,2,3,4}$ Abdulhakeem Althaqafi, ${ }^{2,3,5}$ Abdulfattah Al-Amri, ${ }^{2,3,6}$ \\ Asim Alsaedi, ${ }^{1,2,3}$ Mohammad Abouremsh, ${ }^{7}$ Majid Alshamrani ${ }^{1,2,3}$
}

To cite: Farahat $F$, Althaqafi $A$, Al-Amri A, et al. Cross-sectional seroprevalence study of antibody to Bordetella pertussis toxin in western Saudi Arabia: is there a need for a vaccine booster dose for adolescents and young adults? BMJ Open 2021;11:e042711. doi:10.1136/ bmjopen-2020-042711

- Prepublication history is published online only. To view please visit the journal online (http://dx.doi.org/10.1136/ bmjopen-2020-042711)

Received 12 July 2020 Revised 14 March 2021 Accepted 15 March 2021
Check for updates

(C) Author(s) (or their employer(s)) 2021. Re-use permitted under CC BY-NC. No commercial re-use. See rights and permissions. Published by BMJ.

For numbered affiliations see end of article.

Correspondence to

Dr Fayssal Farahat;

fmfayssal@gmail.com

\section{ABSTRACT}

Objectives The present study was conducted to estimate the seroprevalence of antibody to pertussis toxin among adult populations in western Saudi Arabia.

Design A cross-sectional study.

Setting King Abdulaziz Medical City, Jeddah, western Saudi Arabia. A tertiary care teaching hospital.

Participants A total of 1200 participants (400 healthcare workers, 400 military recruits and 400 blood donors) were included. The majority were male $(79.3 \%)$, and the mean $( \pm \mathrm{SD})$ age was $27.2( \pm 6.7)$ years old.

Interventions The study included the analysis of serum blood samples using commercial ELISA. A consecutive sampling technique was applied.

Primary outcome measures Seropositivity of antipertussis toxin immunoglobulin $\mathrm{G}$ (anti-PT IgG) $\geq 62.5 \mathrm{IU} / \mathrm{mL}$.

Results Antibody titres $\geq 62.5 \mathrm{IU} / \mathrm{mL}$, indicating exposure to Bordetella pertussis infection within the last year, were identified in $12.0 \%(95 \% \mathrm{Cl} 10.2 \%$ to $14.0 \%)$ of the participants. Titres $\geq 125 \mathrm{IU} / \mathrm{mL}$, suggesting recent infection, were detected in $3.5 \%$ (95\% $\mathrm{Cl} 2.5 \%$ to $4.7 \%)$. Seroprevalence of positive IgG antibody titres ( $\geq 62.5 \mathrm{IU} /$ $\mathrm{mL}$ ) was highest among the healthcare workers (HCWs) $(14 \%)$, then the military recruits $(13.5 \%)$ and blood donors $(8.5 \% ; p=0.03)$. The multivariate regression analysis showed association between participants group (HCWs and military), male gender and younger age $(<25$ years old) and higher antibody to pertussis toxin.

Conclusions High pertussis seropositivity was associated with participants' occupation (ie, healthcare workers and military recruits), and anti-PT IgG titre was negatively correlated with age. A substantial deficiency in pertussis reporting in Saudi Arabia has been suggested, with potential increased risk to the most vulnerable populations (ie, infants and elderly). Enhancing the booster dose of pertussis vaccine for adolescents and adults is crucial to minimise the burden of pertussis.

\section{INTRODUCTION}

Pertussis is a highly contagious respiratory disease. Bordetella pertussis (BP) has continued to spread even though infants and children
Strengths and limitations of this study

- This study reported seroprevalence of antibodies to pertussis toxin in high-risk populations in Saudi Arabia.

- This cross-sectional study involved analysing serum blood samples using an ELISA kit with high specificity and sensitivity ( $90 \%$ and $91 \%$, respectively).

- A consecutive convenient sampling technique was applied to select study participants from whom blood samples were routinely obtained.

- A study limitation included a lack of documented information regarding the participants' histories of vaccination or exposure to Bordetella pertussis.

- A nationwide seroprevalence study on a broader age range would better represent the exposure to Bordetella pertussis and disease burden in the country.

have a high vaccine coverage. ${ }^{12}$ Adolescents and adults are identified as the primary source of infection for newborns and young infants. ${ }^{13}$ It is, therefore, of great importance to prevent and early detect pertussis among those populations. ${ }^{4}$ The waning of immunity following pertussis vaccination and lack of administration of booster doses in addition to challenges related to the diagnosis can contribute to the persistence of pertussis. ${ }^{567}$

Clinical diagnosis of pertussis depends on history of cough for at least 2 weeks with no apparent cause in addition to either paroxysms of coughing, inspiratory whoop or posttussive emesis. ${ }^{8}$ For patients with cough for 4 weeks or less, both culture and PCR are performed to confirm pertussis clinical diagnosis. For those with more than 4 weeks of cough, only serology is useful. ${ }^{9}$

Various findings on the prevalence of pertussis have been reported worldwide. A 
study of healthcare workers (HCWs) in Spain reported an overall antipertussis antibody prevalence of $51.7 \% .^{10}$ In Germany, 26.7\% of the studied blood donors had antipertussis toxin IgG (anti-PT IgG) titres that indicate recent exposure. Among Turkish population, Seçkin et $a l^{11}$ found a seropositivity rate of $12.6 \%$ for the group of 10-15years old, whereas all adult subjects were seronegative. In Tunisia, $12.3 \%$ of adolescents (13-18 years) were seropositive with anti-PT IgG antibodies indicative of recent infection/exposure to $\mathrm{BP} .^{12}$ In a Hungarian study, $14.8 \%$ of the adults population screened were seropositive. ${ }^{13}$ The majority of the population investigated $(85.2 \%)$ were considered at increased risk of BP infection due to waning immunity.

In Saudi Arabia, the incidence of pertussis cases reported to the Ministry of Health showed a yearly increase from 2016 to 2019 (namely, 0.022, $0.065,0.095$ and 0.75 per 100000 population over the years). In 2019, 68 pertussis cases were reported in the western region, representing $26.5 \%$ of the country's total reported cases. In the meantime, data on pertussis vaccine coverage were available since 1980 . The vaccine coverage ranged from $94 \%$ to 99\% for the first dose and $92 \%-98 \%$ for the third dose, except in 1980 and 1985, where the coverage reached 53\% and $81 \%$, respectively. ${ }^{14}$ The vaccination coverage among infants during 2019 was $97 \% .{ }^{15}$ A study of a relatively small sample of children $(n=200)$ showed a significantly lower anti-PT IgG among the 17-year-old participants compared with the 6-year-old and 1-year-old participants. ${ }^{16}$ An old report from Saudi Arabia between 1996 and 2004 showed that $22.5 \%$ of the pertussis cases occurred among adolescents $10-19$ years and $12 \%$ among those $\geq 20$ years of age, although most cases occurred among infants less than 6 months of age $(52 \%) .{ }^{17}$ The same study revealed that $30 \%$ of the patients had not received any doses of the vaccine, and $40 \%$ either had not been fully vaccinated or had unknown vaccination statuses. ${ }^{17}$ Pertussis-containing vaccines for adults in Saudi Arabia were recently introduced; however, the administration among adolescents and adults needs further emphasis.

Children in Saudi Arabia receive four doses of pertussiscontaining vaccines by the age of 18 months, and a fifth dose is administered on school entry. Booster doses for older children, adolescents and adults according to the Advisory Committee on Immunization Practices (ACIP) recommendations ${ }^{18}$ is apparently missed. Studies on the incidence of pertussis among the adult population of Saudi Arabia appear to be lacking, and epidemiological data have not supported the impact of the vaccination programme in Saudi Arabia.

The present study was conducted to determine the seroprevalence of anti-PT IgG among blood donors and two high-risk occupational groups (names, HCWs and military recruits) in Jeddah, western Saudi Arabia. Knowledge of the seroprevalence of antibody to pertussis toxin within these populations would reflect the exposure to $\mathrm{BP}$ infection and/or vaccination status and help to assess the distribution of IgG antibodies to pertussis toxin according to the sociodemographic characteristics.

\section{MATERIAL AND METHODS}

The present study was conducted at King Abdulaziz Medical City (KAMC), Ministry of National Guard Health Affairs, Jeddah, Saudi Arabia . KAMC serves the military personnel and employees of the Ministry of National Guard as well as their families. This cross-sectional study was carried out from May 2018 to July 2019 and involved the analysis of serum blood samples obtained from three groups of adult ( $\geq 18$ years old) individuals: (1) blood donors who attended the main blood bank in KAMC-Jeddah; (2) newly recruited HCWs undergoing pre-employment assessment at the employee health clinic in the main hospital, representing Saudi and nonSaudi expatriate workers; and (3) newly recruited military personnel undergoing pre-employment examination at the military pre-employment clinic, representing the male young adult Saudi population, rather than a military population (because blood samples were obtained prior to their first military training).

A consecutive convenient sampling technique was applied to select study participants representing individuals from whom blood samples are routinely obtained. The exclusion criteria included immunocompromised persons and those with recent history of cough or other illnesses. The target sample size was 1200 (400 per participants' group), based on a previous study of HCWs. ${ }^{10}$ Blood samples and participants data were collected prospectively. The first 400 participants identified from each category following study approval were included. Blood samples were stored and processed at the main medical laboratory of KAMC-Jeddah.

Anti-PT IgG concentrations were measured using a commercial ELISA kit (Euroimmun, Lübeck, Germany) according to the manufacturer's protocol. This kit has a specificity of $90 \%$ and a sensitivity of $91 \%$, which were considered to be the highest among 11 commercially available PT antibody kits. ${ }^{19}$

As described in previous studies, anti-PT IgG values were used for data interpretation as follows: $125 \mathrm{IU} / \mathrm{mL}$ (high) to indicate recent (in past 6 months) or active BP infection; $62.5-<125 \mathrm{IU} / \mathrm{mL}$ (moderate) to indicate BP infection within the past year; and $<62.5 \mathrm{IU} / \mathrm{mL}$ to indicate exposure to $\mathrm{BP}$ infection/immunisation $>12$ months prior or never. ${ }^{20} 2122231$ Accordingly, anti-PT IgG level of $62.5 \mathrm{IU} / \mathrm{mL}$ or above was applied to determine the seropositivity.

\section{Ethical approval}

Consent was obtained from each participant to provide information regarding demographic data and immunisation history and to permit antipertussis antibody testing, which is not routinely performed as part of the preemployment examination or blood donation process. 
Patient and public involvement

No patient involved.

\section{Statistical analysis}

Data were analysed using IBM SPSS V.25 software (SPSS Inc, Chicago, USA). Descriptive statistics (frequencies, percentages, means and SD) were used. The seroprevalence proportion was estimated as the number of persons with titres $\geq 62.5 \mathrm{IU} / \mathrm{mL}$ (numerator) divided by the total number of individuals tested (denominator). A $\chi^{2}$ test or Fisher's exact test was performed, as deemed appropriate, to assess frequency distribution of antibody to pertussis toxin (anti-PT) seroprevalence categories (high, moderate and low) according to demographic characteristics (age category, gender, nationality and participants group). A correlation coefficient (Spearman's rank correlation) and a scatterplot were applied to assess the correlation between anti-PT IgG and participant age in years. Non-parametric Kruskall-Wallis and Mann-Whitney tests were applied to compare anti-PT IgG titres among the study groups. Logistic regression analysis was performed to determine risk factors associated with exposure to $\mathrm{BP}$ infection. ORs with their 95\% CI was calculated. Significance was determined at a $\mathrm{p}$ value of $<0.05$.

\section{RESULTS}

The present study included 1200 participants (400 HCWs, 400 military recruits and 400 blood donors). The majority were male $(79.3 \%)$ and of Saudi nationality $(85.5 \%)$. The mean $( \pm \mathrm{SD})$ age of participants was $27.2( \pm 6.7)$ years old and ranged from 18 to 61 years old. Mean age of the military group was 22.9 years compared with 27.9 among the HCWs and 30.8 among the blood donors $(\mathrm{p}=0.001)$.

Histories of pertussis-containing vaccination, according to vaccine documentation or personal recall, were identified in only 14 participants $(1.2 \%)$, all of whom were HCWs. None of the participants reported histories of clinical diagnosis of pertussis.

Anti-PT IgG $\geq 62.5 \mathrm{IU} / \mathrm{mL}$, indicating BP infection within the past year, were identified in $12.0 \%(95 \%$ CI $10.2 \%$ to $14.0 \%$ ) of the participants. High titres $(\geq 125 \mathrm{IU} / \mathrm{mL})$, suggesting recent infection (in the past 6 months), were identified in $3.5 \%$ (95\% CI $2.5 \%$ to $4.7 \%)$. The positive antibody titres $(\geq 62.5 \mathrm{IU} / \mathrm{mL})$ were highest among the HCWs $(14 \%)$, followed by the military recruits $(13.5 \%)$ and blood donors $(8.5 \%)$ ( $p$ value $=0.03) \quad($ table 1$)$. All participants have detectable anti-PT IgG.

The multivariate regression analysis showed association between participants group (HCWs and military) $(\mathrm{OR}=2.52,95 \%$ CI 1.48 to 4.29 ; $\mathrm{OR}=2.73,95 \%$ CI 1.38 to 5.39 , respectively), male gender ( $\mathrm{OR}=2.09,95 \%$ CI 1.18 to 3.69$)$ and younger age ( $<25$ years old) $(\mathrm{OR}=1.88$, $95 \%$ CI 1.01 to 3.48 ), and positive anti-PT antibody titres $(\geq 62.5 \mathrm{IU} / \mathrm{mL})$. However, only the military group $(\mathrm{OR}=2.41,95 \%$ CI 1.09 to 5.32$)$ showed significant

Table 1 Bordetella pertussis serum antibodies according to demographic characteristics of the participants

\begin{tabular}{|c|c|c|c|c|}
\hline \multirow[b]{2}{*}{ Study variables } & \multicolumn{3}{|c|}{ Bordetella pertussis serum antibodies (anti-PT IgG) } & \multirow[b]{2}{*}{$P$ value } \\
\hline & $\begin{array}{l}\text { High }(n=42) \\
(\geq 125 \mathrm{IU} / \mathrm{mL}) \\
(3.5 \%) \\
n(\%)\end{array}$ & $\begin{array}{l}\text { Moderate }(\mathrm{n}=102) \\
(62.5-<125 \mathrm{IU} / \mathrm{mL}) \\
(8.5 \%) \\
\mathrm{n}(\%)\end{array}$ & $\begin{array}{l}\text { Low }(\mathrm{n}=1056) \\
(<62.5 \mathrm{IU} / \mathrm{mL}) \\
(88.0 \%) \\
\mathrm{n}(\%)\end{array}$ & \\
\hline \multicolumn{5}{|l|}{ Participants group } \\
\hline Healthcare workers $(n=400)$ & $12(28.6)$ & $44(43.1)$ & $344(32.6)$ & \\
\hline Blood donors $(n=400)$ & $9(21.4)$ & $25(24.5)$ & $366(34.7)$ & \\
\hline \multicolumn{5}{|l|}{ Gender } \\
\hline Male $(n=952)$ & $34(81.0)$ & $84(82.4)$ & $834(79.0)$ & 0.70 \\
\hline Female $(n=248)$ & $8(19.0)$ & $18(17.6)$ & $222(21.0)$ & \\
\hline$>30(n=270)$ & $3(7.1)$ & $26(25.5)$ & $241(22.8)$ & \\
\hline Age in years, mean (SD) & $25.1(4.2)$ & $27.3(6.3)$ & $27.3(6.8)$ & 0.13 \\
\hline \multicolumn{5}{|l|}{ Nationality } \\
\hline Saudi (n=1026) & $36(85.7)$ & $92(90.2)$ & $898(85.0)$ & 0.37 \\
\hline Non-Saudi $(n=174)$ & $6(14.3)$ & $10(9.8)$ & $158(15.0)$ & \\
\hline
\end{tabular}

${ }^{*}+$ Mean age of the military group was 22.9 years compared with 27.9 years among the HCWs and 30.8 years among the blood donors $(p=0.001)$.

anti-PT IgG, antipertussis toxin lgG. 
Table 2 Multivariate logistic regression analysis of factors associated with seropositive pertussis antibodies

\begin{tabular}{|c|c|c|c|c|}
\hline \multirow[b]{2}{*}{ Variables } & \multicolumn{2}{|c|}{ High/moderate versus low } & \multicolumn{2}{|c|}{ High versus moderate/low } \\
\hline & OR $(95 \% \mathrm{Cl})$ & $P$ value & OR (95\% Cl) & P value \\
\hline \multicolumn{5}{|l|}{ Participants group } \\
\hline Military new recruits $(n=400)$ & 2.73 (1.38 to 5.39$)$ & 0.004 & 2.41 (1.09 to 5.32$)$ & 0.03 \\
\hline Blood donors $(n=400)$ & Ref & - & Ref & - \\
\hline Male $(n=952)$ & 2.09 (1.18 to 3.69$)$ & 0.01 & 0.89 (0.25 to 3.13$)$ & 0.85 \\
\hline Female $(n=248)$ & Ref & - & Ref & - \\
\hline \multicolumn{5}{|l|}{ Age category (years) } \\
\hline$<25(\mathrm{n}=588)$ & $1.88(1.01$ to 3.48$)$ & 0.045 & 1.21 (0.39 to 3.73$)$ & 0.74 \\
\hline$\geq 25(\mathrm{n}=612)$ & Ref & - & Ref & - \\
\hline \multicolumn{5}{|l|}{ Nationality } \\
\hline Non-Saudi $(n=174)$ & Ref & - & Ref & - \\
\hline
\end{tabular}

association with higher anti-PT antibodies $(\geq 125 \mathrm{IU} / \mathrm{mL})$ (table 2).

The scatterplot in figure 1 depicts the correlation between participants' age in years and anti-PT IgG titres. The Spearman's rank correlation coefficient showed a significantly negative correlation $\left(r_{s}=-0.1, p=0.001\right)$ between these two variables. Furthermore, majority of the cases above age of 30 years $(89.3 \%)$ have low titres $(<62.5 \mathrm{IU} / \mathrm{mL})$.
The median and IQR of the anti-PT IgG titres are described for each participants group in figure 2. The titres of the HCWs (median=39.3, IQR=12.8) and military recruits (median=39.2, $\mathrm{IQR}=12.3$ ) were significantly higher than those of the blood donors (median=36.4, $\mathrm{IQR}=12.4 ; \mathrm{p}=0.001)$. Pairwise comparison showed no statistically significant differences between the titre of the HCWs and those of the military recruits $(p=0.60)$; however, titres of each the HCWs and military groups

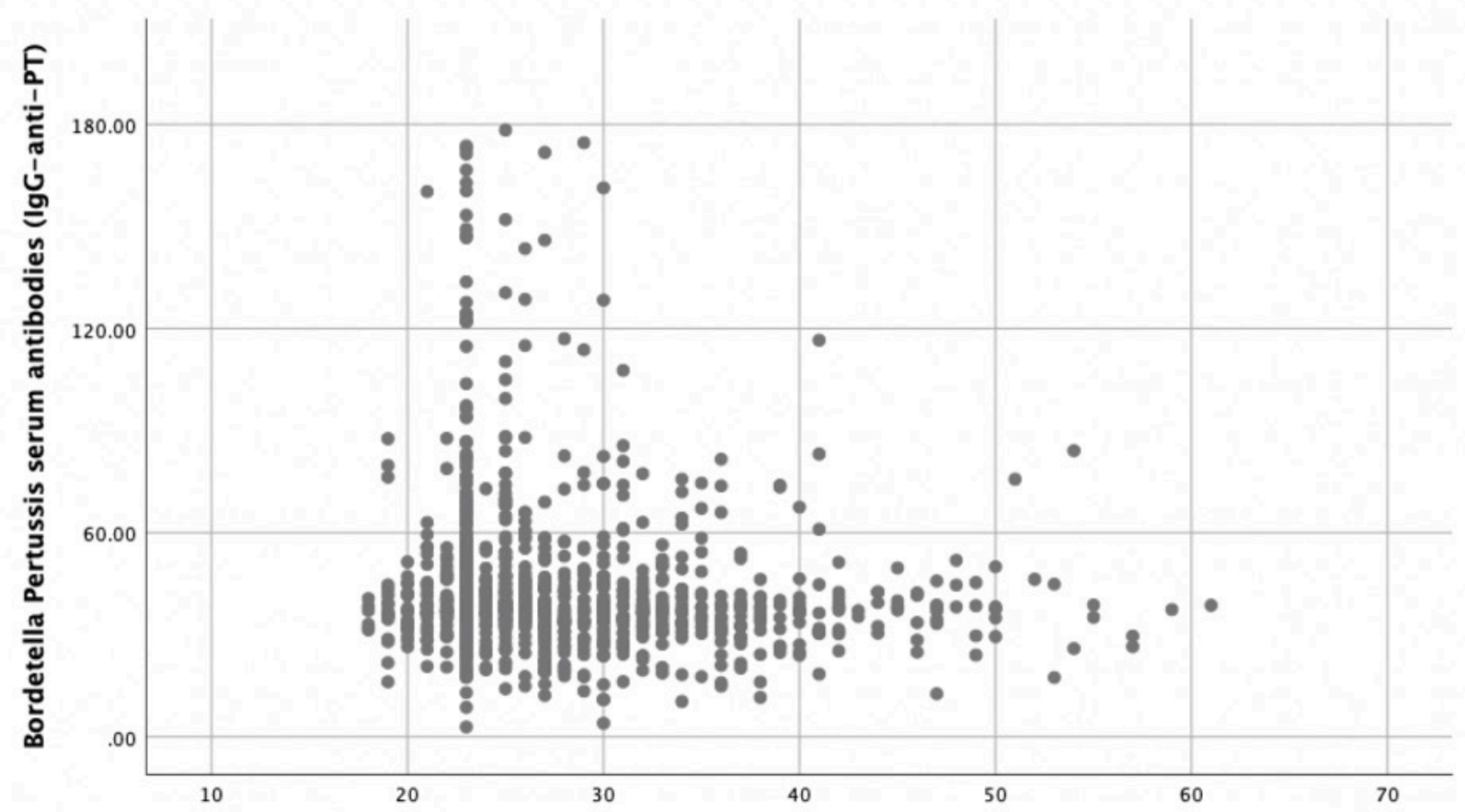

Age in years

Figure 1 Distribution of Bordetella pertussis antibodies (anti-PT-IgG, IU/mL) according to age (years) of the participants (Spearman's correlation coefficient $=-0.11, \mathrm{p}=0.001$ ). Data of 13 cases with anti-PT IgG levels $>200 \mathrm{IU} / \mathrm{mL}$ are not shown in the scatterplot (their age range was between 20-44 years old). anti-PT IgG, antipertussis toxin lgG. 


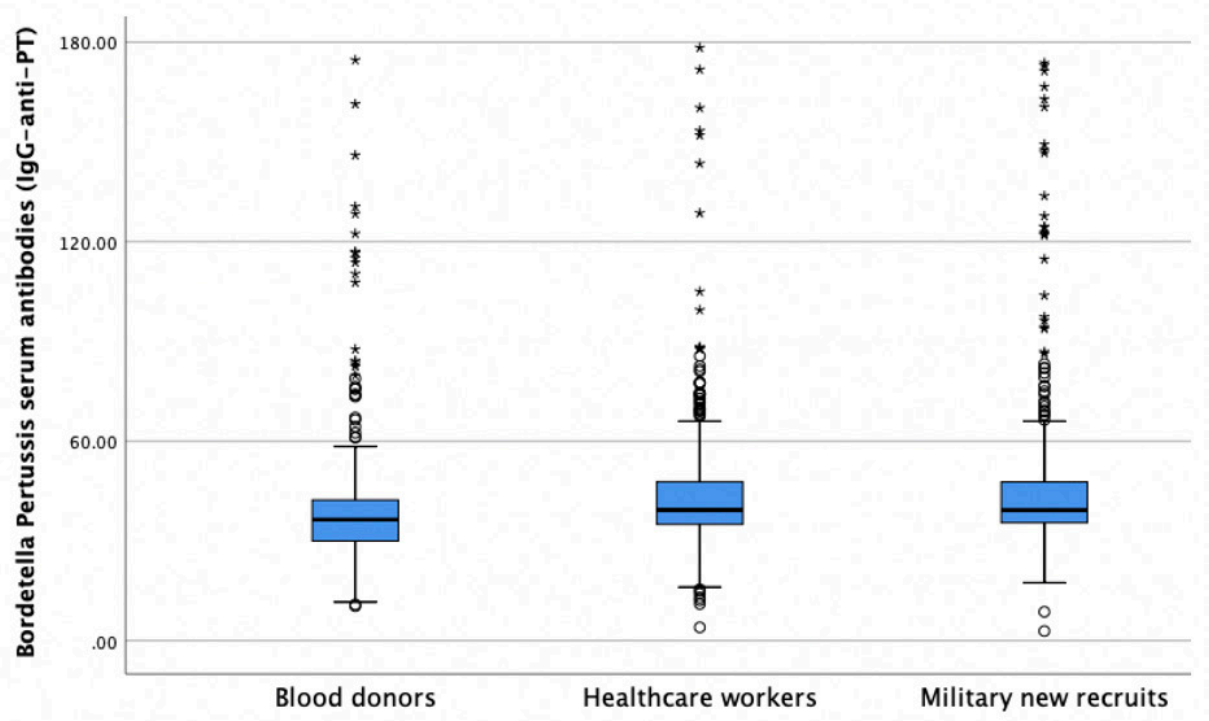

Figure 2 Boxplot of Bordetella pertussis antibodies (anti-PT IgG) distributed by participants category. Kruskall-Wallis test, $p$ value $=0.001$ (Mann-Whitney test to compare blood donor vs HCWs, $p$ value $=0.001$; blood donor vs military personnel, $p$ value $=0.001$; and HCWs vs military, $p$ value=0.61) (statistical tests were performed on results of 1200 participants). Data of 13 cases with anti-PT lgG levels $>200 \mathrm{IU} / \mathrm{mL}$ ) are not shown in the boxplot (three blood donors, five HCWs and five military recruits). * indicates extreme values. o indicates outlier values. anti-PT IgG, antipertussis toxin IgG; HCWs, healthcare workers.

were significantly different from those of the blood donor group ( $\mathrm{p}=0.001$; figure 2$)$.

\section{DISCUSSION}

The present study determined the seroprevalence of anti-PT IgG within three adult populations from whom blood samples were routinely obtained for preemployment medical assessment (HCWs and military recruits) or blood donation. Overall, $12.0 \%$ of these participants were seropositive for anti-PT IgG, and the majority were considered at risk of BP infection (88\%). The reported prevalence of seropositivity has varied across studies depending on the assays and cut-offs used ${ }^{24}$ as well as the participants' pertussis infection and vaccination histories. ${ }^{25}$

The percentage of participants in the present study with evidence of recent exposure to $\mathrm{BP}$ within the past 6 months $(3.5 \%)$ was similar to those found in previous studies, which have reported rates of pertussis infection ranging from $1 \%$ to $10 \%$ in the adult population. ${ }^{13} 26-32$ Vaccination against pertussis among adolescents and adults is not optimal in several countries worldwide. ${ }^{33}$ Many countries also shifted from the whole-cell (wP) to the acellular pertussis $(\mathrm{aP})$ vaccines. This shift was not consistent among countries and has been implicated as a contributing factor for pertussis infection resurgence in these countries. ${ }^{34} 35$

The present study detected higher anti-PT IgG titres among younger participants. This observation was consistent with those of previous studies. ${ }^{36}{ }^{37}$ However, some other studies have reported increased rates of seropositivity in older populations. ${ }^{27} 3813$ In areas with comprehensive childhood immunisation, it could be concluded that elevated antibodies among younger individuals are more often related to vaccination, whereas antibodies among older people are more often due to previous infection. ${ }^{13}$

The last dose of the pertussis vaccine is administered at the age of 4-6years, according to the childhood national immunisation schedule of Saudi Arabia. The present study included an adult population ranging in age from 18 to 61 years old, with almost $80 \%$ being less than 30 years old. Pertussis booster doses for adolescents and adults are not yet well implemented in Saudi Arabia. Therefore, the high titres observed in this study were more likely due to recent infections than recent immunisations. These findings emphasise the magnitude of the burden of pertussis infection spread in the community and high-risk populations. The implementation of booster vaccination recommendations for adolescents and adults will significantly reduce such burden and ensure protection of the at-risk individuals, including infants and the elderly.

Our data revealed that most of the participants with high anti-PT IgG titres suggesting exposure to BP infection within 6 months or 1 year were the military recruits and HCWs. The military participants in the current study are more representative of the young adult population, 21-23 years old, with a high school level of education. The argument about the impact of childhood immunisation among this relatively young population could also be discussed, taking into consideration the high vaccination coverage (above 95\%) in the country since 1995 and that those population received the whole-cell pertussis vaccine during childhood, which reported to have longer lasting immunity than the acellular vaccine. ${ }^{14}$ Previous studies have shown that despite the waning of antibodies, the clinical efficacy of the $\mathrm{wP}$ vaccine remained at $92 \%$ 
6 years after the last dose. ${ }^{39}$ Ten years have been suggested for waning immunity following the aP vaccine. ${ }^{40}$ Also, considering the impact of immunisation for high titres among the relatively older age participants of the HCWs (age range 21-55 years, average age 27.9) and the blood donors group (age range 18-61 years, average age 30.8 ) is unlikely.

There is no cut-off level of anti-PT IgG to determine the need for a booster dose; accordingly, following the ACIP recommendations for adolescents and adults will ensure protection throughout life in addition to other factors that mediate protection against pertussis. ${ }^{4142}$

Anti-PT IgG levels significantly differed according to gender in the present study. Similarly, a significantly higher prevalence of seropositivity has been reported among males than among females in studies from the Netherlands, ${ }^{28}$ Mexico, ${ }^{36}$ Korea ${ }^{38}$ and Hungary. ${ }^{13}$ However, no significant associations of this kind were found in other studies from Denmark, ${ }^{30}$ Gambia $^{43}$ and China. ${ }^{32}$ The variation in these findings could reflect differences in vaccination coverage and disease exposure between different settings rather than gender effects.

According to the Saudi Ministry of Health (MOH) statistics, the annual incidence rate of reported pertussis cases increased from 0.003 per 100000 individuals in 2014 to 0.095 per 100000 individuals in $2018 .{ }^{15}$ Comparison between the present results and the incidence rate estimated by the $\mathrm{MOH}$ suggested significant under-reporting of pertussis cases in Saudi Arabia. Barkoff $e t a t^{4}$ reviewed studies of pertussis seroprevalence from different countries and highlighted a major discrepancy between pertussis incidence rates based on reported data, which are usually low $(<1-10 / 100000)$, and a rate based on serological surveillance as an estimate of the real disease burden. Similar under-reporting concern, particularly among adults has been raised through several other studies. ${ }^{44} 134546$ Adults with pertussis infection usually have mild symptoms compared with infants and can be easily diagnosed as a common cold. ${ }^{24}$

Findings of the current study may be limited because of the lack of documented information regarding the participants' histories of vaccination or exposure to $\mathrm{BP}$ infection. Additionally, the inclusion of all-male military recruits may have led to a higher proportion of males than females in the study sample. However, the separation of the sample into three sample groups allowed for the analysis of data from different populations with different risks of exposure, age ranges and degrees of vaccination coverage. Moreover, one strength of this study was the use of a kit with the highest specificity and sensitivity among all commercially available kits for PT antibodies. $^{19}$

In conclusion, the present study determined a seropositivity of $12.0 \%$ among the studied adult populations. Overall, the majority of the participants had low antibody levels due to waning immunity following distant vaccination or infection exposure. High seropositivity was related to participants' occupation, with increased anti-PT IgG titre among HCWs and military recruits than blood donors. Moreover, anti-PT IgG titres were negatively correlated with participants' ages.
A comparison of the presently identified seropositivity rate with the reported by the MOH in Saudi Arabia indicated significant underdiagnosis and under-reporting of pertussis in Saudi Arabia. A nationwide seroprevalence in a wider age range is suggested for better assessment of the magnitude of exposure and impact of vaccination interventions as well. However, seroepidemiological surveys of blood donors ${ }^{47}$ and high-risk occupational groups (eg, HCWs and military personnel) may provide a more feasible and realistic estimate of pertussis infection. Immunity from infection or vaccination with pertussis is not permanent, ${ }^{48}$ and the high circulation of this pathogen represents a threat to the most susceptible populations (ie, infants and the elderly). The introduction of booster doses of pertussis vaccine for adolescents, and young adults, including pregnant women, should be enhanced as an effective strategy to minimise the risk of transmission and burden associated with pertussis infection.

\section{Author affiliations}

${ }^{1}$ Infection Prevention and Control Program, King Abdulaziz Medical City, Ministry of National Guard Health Affairs, Riyadh/Jeddah, Saudi Arabia

${ }^{2}$ King Saud bin Abdulaziz University for Health Sciences, Riyadh/Jeddah, Saudi Arabia

${ }^{3}$ King Abdullah International Medical Research Center, Riyadh/Jeddah, Saudi Arabia ${ }^{4}$ Public Health and Community Medicine, Faculty of Medicine, Menoufia University, Egypt

${ }^{5}$ Department of Medicine, King Abdulaziz Medical City, Ministry of National Guard Health Affairs, Jeddah, Saudi Arabia

${ }^{6}$ Medical Laboratory, King Abdulaziz Medical City, Ministry of National Guard Health Affairs, Jeddah, Saudi Arabia

${ }^{7}$ Military Field Medicine, King Abdulaziz Medical City, Ministry of National Guard Health Affairs, Jeddah, Saudi Arabia

Acknowledgements The authors would like to thank the staff of the serology laboratory (Major Naser Alhamdan and Mr Wail Almazain) who performed the analysis of the blood samples, and Ms Omaima Hassan from the Infection Prevention and Control Department for her support in the data collection and entry.

Contributors FF: conceived the study, data analysis and interpretation, drafted and critically revised the final version of the manuscript. AAlt: conceived the study and critically revised the final version of the manuscript. AA: supervised the laboratory analysis and interpreted the results. AAls: critically revised the final version of the manuscript. MAb: participated in the data collection. MAl: critically revised the final version of the manuscript.

Funding This work was supported by GlaxoSmithKline Biologicals SA (GSK Study Identifier: 205750). This project was part of the Independent Supported Studies programme, where GSK is not responsible for the design, execution, analysis or interpretation of results.

\section{Competing interests None declared.}

Patient and public involvement Patients and/or the public were not involved in the design, or conduct, or reporting, or dissemination plans of this research.

Patient consent for publication Not required.

Ethics approval The present study was approved by the Institutional Review Board of the King Abdullah International Medical Research Center, Ministry of National Guard Health Affairs (CT17/031/J).

Provenance and peer review Not commissioned; externally peer reviewed.

Data availability statement All data relevant to the study are included in the article or uploaded as supplementary information.

Open access This is an open access article distributed in accordance with the Creative Commons Attribution Non Commercial (CC BY-NC 4.0) license, which permits others to distribute, remix, adapt, build upon this work non-commercially, and license their derivative works on different terms, provided the original work is properly cited, appropriate credit is given, any changes made indicated, and the use is non-commercial. See: http://creativecommons.org/licenses/by-nc/4.0/. 
ORCID iD

Fayssal Farahat http://orcid.org/0000-0001-5186-2872

\section{REFERENCES}

1 von König CHW, Halperin S, Riffelmann M, et al. Pertussis of adults and infants. Lancet Infect Dis 2002;2:744-50.

2 Meeting of the strategic Advisory group of experts on immunization, October 2014 - conclusions and recommendations. Weekly Epidemiological Record;89:561-76 https://apps.who.int/iris/handle/ $10665 / 242296$

3 Wiley KE, Zuo Y, Macartney KK, et al. Sources of pertussis infection in young infants: a review of key evidence informing targeting of the cocoon strategy. Vaccine 2013;31:618-25.

4 Hewlett EL, Edwards KM. Clinical practice. Pertussis-not just for kids. N Engl J Med 2005;352:1215-22.

5 Mooi FR, Van Der Maas NAT, De MELKER HE. Pertussis resurgence: waning immunity and pathogen adaptation - two sides of the same coin. Epidemiol Infect 2014;142:685-94.

6 Cherry JD. Epidemic pertussis in 2012 - the resurgence of a vaccine-preventable disease. New England Journal of Medicine 2012;367:785-7.

7 Shamsizadeh A, Nikfar R, Yusefi H, et al. Seroprevalence of pertussis antibodies in 6-17-year-old students in Ahvaz, south-west Islamic Republic of Iran. East Mediterr Health J 2014;20:623-6.

8 Centers for Disease Control. Pertussis | whooping cough | causes and transmission. Available: https://www.cdc.gov/pertussis/about/ causes-transmission.html [Accessed 8 Mar 2021].

9 Cornia PLB. Pertussis infection in adolescents and adults: clinical manifestations and diagnosis. UpToDate, 2021. Available: https:// www.uptodate.com/contents/pertussis-infection-in-adolescentsand-adults-clinical-manifestations-and-diagnosis [Accessed $8 \mathrm{Mar}$ 2021].

10 Urbiztondo L, Broner S, Costa J, et al. Seroprevalence study of $B$. pertussis infection in health care workers in Catalonia, Spain. Hum Vaccin Immunother 2015;11:293-7.

11 Seçkin H, ÖRMECi AR, Sandal G, et al. [Seroepidemiology of pertussis in 10-15 years old healthy children in Isparta province, Turkey]. Mikrobiyol Bul 2013;47:507-13.

12 Ben Fraj I, Zghal M, Hsairi M, et al. Seroprevalence of Bordetella pertussis toxin antibodies in children and adolescents in Tunis, Tunisia. Epidemiol Infect 2019;147:e199.

13 Torzsa P, Devadiga R, Tafalla M. Seroprevalence of Bordetella pertussis antibodies in adults in Hungary: results of an epidemiological cross-sectional study. BMC Infect Dis 2017;17:242.

14 WHO. Who vaccine-preventable diseases: monitoring system. 2020 global summary, 2020. Available: https://apps.who.int/immunization monitoring/globalsummary/countries?countrycriteria\%5Bcountry\% 5D\%5B\%5D=SAU\&commit=OK [Accessed 8 Mar 2021].

15 Ministry of health, Kingdom of Saudi Arabia. statistical yearbook, 2018. Available: https://www.moh.gov.sa/en/Ministry/Statistics/book/ Documents/book-Statistics.pdf

16 Al-Mazrou YY, Khalil MK, Elgizouli SA, et al. Diphtheria, pertussis, and tetanus serosurvey in Saudi children. Saudi Med J 2007:28:1230-3.

17 Al-Tawfiq JA, AbuKhamsin A. Bordetella pertussis infection in a highly vaccinated population in Saudi Arabia, 1996-2004. J Infect 2007:55:249-53.

18 Wirsing von König $\mathrm{CH}$. The immunological basis for immunization series - Module 4: Pertussis Update 2009. World Heal Organ, 2010. Available: https://apps.who.int/iris/bitstream/handle/10665/44311/ 9789241599337_eng.pdf?sequence=1 [Accessed 8 Mar 2021].

19 Riffelmann M, Thiel K, Schmetz J, et al. Performance of Commercial Enzyme-Linked Immunosorbent Assays for Detection of Antibodies to Bordetella pertussis. J Clin Microbiol 2010;48:4459-63.

20 de Melker HE, Versteegh FGA, Schellekens JFP, et al. The incidence of Bordetella pertussis infections estimated in the population from a combination of serological surveys. J Infect 2006;53:106-13.

21 Pebody RG, Gay NJ, Giammanco A, et al. The seroepidemiology of Bordetella pertussis infection in Western Europe. Epidemiol Infect 2005;133:159-71.

22 Jõgi P, Oona M, Toompere K, et al. Seroprevalence of IgG antibodies to pertussis toxin in children and adolescents in Estonia. Vaccine 2014;32:5311-5.

23 Jõgi P, Oona M, Toompere K, et al. Estimated and reported incidence of pertussis in Estonian adults: a seroepidemiological study. Vaccine 2015;33:4756-61.
24 Barkoff A-M, Gröndahl-Yli-Hannuksela K, He Q. Seroprevalence studies of pertussis: what have we learned from different immunized populations. Pathog Dis 2015;73:ftv050.

25 Wirsing von König C-H. Pertussis diagnostics: overview and impact of immunization. Expert Rev Vaccines 2014;13:1167-74.

26 Wanlapakorn N, Ngaovithunvong V, Thongmee T, et al. Seroprevalence of antibodies to pertussis toxin among different age groups in Thailand after 37 years of universal whole-cell pertussis vaccination. PLoS One 2016;11:e0148338.

27 Palazzo R, Carollo M, Fedele G, et al. Evidence of increased circulation of Bordetella pertussis in the Italian adult population from seroprevalence data (2012-2013). J Med Microbiol 2016;65:649-57.

28 de Greeff SC, de Melker HE, van Gageldonk PGM, et al. Seroprevalence of pertussis in the Netherlands: evidence for increased circulation of Bordetella pertussis. PLoS One 2010;5:e14183.

29 Huygen K, Rodeghiero C, Govaerts D, et al. Bordetella pertussis seroprevalence in Belgian adults aged 20-39 years, 2012. Epidemiol Infect 2014;142:724-8.

30 Rønn PF, Dalby T, Simonsen J, et al. Seroepidemiology of pertussis in a cross-sectional study of an adult general population in Denmark. Epidemiol Infect 2014;142:729-37.

31 Xu Y, Wang L, Xu J, et al. Seroprevalence of pertussis in China need to improve vaccination strategies. Hum Vaccines Immunother 2014;1091:192-8.

32 Chen Z, Zhang J, Cao L, et al. Seroprevalence of pertussis among adults in China where whole cell vaccines have been used for 50 years. J Infect 2016;73:38-44.

33 WHO. Pertussis vaccines: who position paper, August 2015-Recommendations. Weekly epidemiological;2015:433-60 https://www.who.int/wer/2015/wer9035.pdf?ua=1

34 Ausiello CM, Cassone A. Acellular pertussis vaccines and pertussis resurgence: revise or replace? MBio 2014;5:e01339-14.

35 Chen Z, He Q. Immune persistence after pertussis vaccination. Hum Vaccin Immunother 2017;13:744-56.

36 Conde-Glez C, Lazcano-Ponce E, Rojas R, et al. Seroprevalence of Bordetella pertussis in the Mexican population: a cross-sectional study. Epidemiol Infect 2014;142:706-13.

37 Pavlopoulou ID, Syriopoulou V, Daikos GL, et al. Pertussis seroprevalence in different age groups in Greece. Scand $\mathrm{J}$ Infect Dis 2007;39:14-18

38 Lee SY, Han SB, Bae EY, et al. Pertussis seroprevalence in Korean adolescents and adults using anti-pertussis toxin immunoglobulin G. $J$ Korean Med Sci 2014;29:652-6.

39 Nguyen AW, Wagner EK, Laber JR, et al. A cocktail of humanized anti-pertussis toxin antibodies limits disease in murine and baboon models of whooping cough. Sci Transl Med 2015;7:316ra195.

40 Mertsola J, Van Der Meeren O, He Q, et al. Decennial administration of a reduced antigen content diphtheria and tetanus toxoids and acellular pertussis vaccine in young adults. Clin Infect Dis 2010;51:656-62

41 Cherry JD, Gornbein J, Heininger U, et al. A search for serologic correlates of immunity to Bordetella pertussis cough illnesses. Vaccine 1998;16:1901-6.

42 Storsaeter J, Hallander HO, Gustafsson L, et al. Levels of antipertussis antibodies related to protection after household exposure to Bordetella pertussis. Vaccine 1998:16:1907-16.

43 Scott S, Van Der Sande M, Faye-Joof T, et al. Seroprevalence of pertussis in the Gambia: Eevidence for continued circulation of Bordetella pertussis despite high vaccination rates. Pediatr Infect Dis $J$ 2015;34:333-8.

44 Kim DK, Riley LE, Harriman KH, et al. Advisory Committee on immunization practices recommended immunization schedule for adults aged 19 years or older - United States, 2017. MMWR Morb Mortal Wkly Rep 2017;66:136-8.

45 Healy CM, Rench MA, Wootton SH, et al. Evaluation of the impact of a pertussis cocooning program on infant pertussis infection. Pediatr Infect Dis J 2015;34:22-6.

46 Safadi MAP. Control of pertussis in infants: time has finally come? Expert Rev Vaccines 2015;14:781-3.

47 Kennerknecht N, Riffelmann M, Voelker U, et al. Pertussis surveillance by small serosurveys of blood donors. Epidemiol Infect 2018;146:1807-10.

48 Cherry JD. Pertussis: challenges today and for the future. PLoS Pathog 2013;9:e1003418. 